\title{
Reporting long-term effects of metabolic stress on human ovary carcinoma
}

\author{
Maryam Nakhjavani ${ }^{1, *}$, Farshad H. Shirazi ${ }^{1,2}$ \\ 1 Department of Toxico-Pharmacology, Shahid Beheshti School of Pharmacy, Shahid Beheshti University of Medical \\ Sciences, Tehran, Iran. \\ 2 Pharmaceutical Sciences Research Center, Shahid Beheshti Medical University, Tehran, Iran. \\ * Correspondence: mn.nakhjavani@gmail.com (M.N.); Current address: The University of Adelaide, North Terrace \\ Campus, Adelaide, SA 5000.; ORCID No: 0000-0002-5357-7167.
}

Received: 11 August 2017 / Revised: 16 October 2017 / Accepted: 17 October 2017

\begin{abstract}
A key challenge in cancer treatment is the wide range of cancer cells' behavior towards chemotherapy and treatment procedures, which makes the outcomes of treatment often unpredictable, accompanied by cancer resistance and recurrence. One underlying reason is that tumor is a heterogeneous tissue. The cells within a tumor are at different metabolic states and hence behave differently from another and towards the chemotherapeutics. Many of the cells in the inner layers of a tumor lack an appropriate growth condition. However, upon tumor shrinkage, they can regrow and finally cause tumor resistance or recurrence. In the current study, for the first time, long term effects of different levels of metabolic stress on human ovary cancer cell line, A2780, is reported. In this in vitro model, the cells exposed to $10 \%$ serum were considered as control and metabolic stress was induced at $0.5,0.25$ and $0 \%$ serum for 1-6 days. In this 6-day period, cells' morphology changes, size, cell cycle, mitochondrial function and protein content was measured at 24 -hour intervals. Also, cells ability to recur was assessed with the above tests in a 24 -hour release in $10 \%$ serum. The results of this study showed that A2780 cells show resistant features against metabolic stress and this longterm stress does not stop cells recurrence. These results indicate that in order to have a successful tumor treatment, a modified chemotherapy procedures against different types of cells laying within one tumor is required.
\end{abstract}

KEYWORDS: Neoplasm; Metabolic Stress; Long-term; Ovary; A2780.

\section{INTRODUCTION}

A key challenge in cancer treatment is cancer resistance against chemotherapeutics and cancer recurrence, which is usually harder to treat. Many researchers around the world are focusing on finding new treatments to this disease [1-3]. The medicinal chemists synthesize novel structures, pharmacognosists look for new effective herbal extracts, nano-technologists apply nano science into pharmaceuticals and oncologists [4-10] and clinical researchers try newer chemotherapy regimen [1-3, 11-13]. However, a successful cancer treatment is still a summit to achieve. The reason behind a tumor not responding as efficient as the clinicians expect is laid within the tumor itself.

Nowadays, the heterogeneity of a tumor has gained more attention [14-17]. Cells living on the outer layers of a tumor have a better chance for proliferation and growth, as they have easier access to oxygen and nutrition, bear less physical stress and discard metabolic waste more easily. The deeper the cells are located within a tumor, the more their metabolic state is stressed and changed. This stress does not always kill the cells. In fact, this could be an underlying reason why the tumor does not respond to chemotherapy uniformly and why it recurs with a more resistant characteristic.

Ovarian cancer is the fifth cause of cancer death in women [18]. Unfortunately, similar to many other tumors, the survival rate in this disease decreases as the tumor stage increases [19, 20]. In the current study, as a follow-up to our previous studies [21,22], we have focused on this cancer and have focused on an in vitro model of human ovary carcinoma, bearing different levels of metabolic stress.

How to cite this article: Nakhjavani M, Shirazi FH. Reporting long-term effects of metabolic stress on human ovary carcinoma. Marmara Pharm J. 2018; 22 (2): 152-162. 


\section{RESULTS}

As mentioned earlier in the methods section, A2780 cells underwent metabolic stress in low serum concentrations, while control cells were exposed to media containing 10\% FBS. At the early plateau phase, the supernatant media of the cells was replaced with media containing 10\% FBS. Starved cells also accumulated in $\mathrm{G}_{1}$ phase of the cell cycle (Table 1 and Figure 1). Maximum $\mathrm{G}_{1}$ accumulation (about 72\%) happened in cells starved at $0.5 \%$ FBS and in a 3, 4, 5 and 6-day starvation. It took a longer period of time for the cells starved at $0.25 \%$ FBS to reach the maximum $G_{1}$ accumulation $(65.25 \pm 1.06)$. For both cases, within this period of time, percent of cells in S phase decreased gradually (Table 1) and the mean cell size also decreased substantially, though not significantly (Table 2).

As Table 1 shows, A2780 cells' accumulation in $\mathrm{G}_{1}$ phase increased gradually for the first 5 days of the study, reaching to $67.75 \pm 0.30$ and on the last day of the study a dramatic increase in sub-G $\mathrm{G}_{1}$ population $(27.89 \pm 0.04)$ was observed along with decrease in $G_{1}$ population (48.01 \pm 7.58$)$. This is while the count of live cells (Figures 2 and 3), mitochondrial function (Figure 4) and cells' protein content (Figure 5), together with cells' mean size (Table 2) were decreasing.

Table 1. A2780 cell distribution in different phases of the cell cycle following exposure to $10,0.5,0.25$ and $0 \%$ serum for 1 to 6 days.

\begin{tabular}{|c|c|c|c|c|c|}
\hline \multirow{2}{*}{ FBS $\%$} & \multirow{2}{*}{$\begin{array}{c}\text { Time after } \\
\text { starvation (day) }\end{array}$} & \multicolumn{4}{|c|}{ Cell \% in cell cycle phases } \\
\hline & & Sub-G & $\mathrm{G}_{1}$ & $S$ & $\mathrm{G}_{2} \mathrm{M}$ \\
\hline \multirow{6}{*}{10} & 1 & $4.67 \pm 0.02$ & $42.39 \pm 0.91$ & $42.45 \pm 5.77$ & $8.11 \pm 7.09$ \\
\hline & 2 & $11.77 \pm 1.44$ & $45.43 \pm 0.72$ & $31.99 \pm 3.21$ & $9.37 \pm 1.34$ \\
\hline & 3 & $6.65 \pm 0.33$ & $55.90 \pm 2.47$ & $25.71 \pm 1.23$ & $9.95 \pm 3.20$ \\
\hline & 4 & $7.65 \pm 0.36$ & $63.08 \pm 4.24$ & $19.45 \pm 0.01$ & $8.23 \pm 4.08$ \\
\hline & 5 & $10.14 \pm 0.51$ & $67.75 \pm 0.30$ & $14.79 \pm 1.64$ & $6.47 \pm 1.92$ \\
\hline & 6 & $27.89 \pm 0.04$ & $48.01 \pm 7.58$ & $20.02 \pm 5.25$ & $2.82 \pm 1.40$ \\
\hline \multirow{6}{*}{0.5} & 1 & $4.19 \pm 1.93$ & $41.76 \pm 3.61$ & $47.65 \pm 0.83$ & $4.75 \pm 2.25$ \\
\hline & 2 & $5.59 \pm 0.70$ & $57.71 \pm 2.65$ & $27.38 \pm 1.23$ & $7.81 \pm 3.92$ \\
\hline & 3 & $6.44 \pm 0.13$ & $70.24 \pm 0.14$ & $14.17 \pm 1.98$ & $8.58 \pm 1.64$ \\
\hline & 4 & $6.74 \pm 0.74$ & $71.80 \pm 1.49$ & $12.75 \pm 0.97$ & $7.71 \pm 1.59$ \\
\hline & 5 & $7.79 \pm 0.02$ & $72.56 \pm 2.14$ & $10.67 \pm 2.22$ & $8.47 \pm 0.77$ \\
\hline & 6 & $8.28 \pm 0.81$ & $72.65 \pm 0.40$ & $13.95 \pm 0.21$ & $4.25 \pm 1.25$ \\
\hline \multirow{6}{*}{0.25} & 1 & $4.44 \pm 0.11$ & $49.96 \pm 0.54$ & $42.91 \pm 1.68$ & $2.19 \pm 2.06$ \\
\hline & 2 & $5.36 \pm 0.94$ & $54.18 \pm 0.38$ & $31.92 \pm 0.82$ & $7.18 \pm 2.02$ \\
\hline & 3 & $5.31 \pm 0.12$ & $58.13 \pm 2.31$ & $25.09 \pm 2.70$ & $9.45 \pm 0.06$ \\
\hline & 4 & $7.64 \pm 3.76$ & $61.11 \pm 3.34$ & $21.77 \pm 3.04$ & $8.20 \pm 3.06$ \\
\hline & 5 & $10.27 \pm 1.66$ & $65.25 \pm 1.06$ & $13.17 \pm 2.07$ & $10.63 \pm 1.54$ \\
\hline & 6 & $11.81 \pm 1.05$ & $59.06 \pm 4.69$ & $21.39 \pm 3.03$ & $6.37 \pm 2.41$ \\
\hline \multirow{6}{*}{0} & 1 & $3.94 \pm 0.48$ & $50.25 \pm 0.95$ & $38.38 \pm 0.15$ & $5.95 \pm 1.49$ \\
\hline & 2 & $7.77 \pm 0.92$ & $48.17 \pm 1.59$ & $35.74 \pm 1.11$ & $7.27 \pm 3.52$ \\
\hline & 3 & $5.42 \pm 1.98$ & $50.91 \pm 1.52$ & $28.39 \pm 2.19$ & $13.82 \pm 2.80$ \\
\hline & 4 & $11.36 \pm 0.01$ & $48.95 \pm 2.26$ & $28.34 \pm 0.20$ & $9.52 \pm 2.02$ \\
\hline & 5 & $12.06 \pm 1.95$ & $50.98 \pm 3.93$ & $26.31 \pm 0.53$ & $9.35 \pm 4.94$ \\
\hline & 6 & $13.46 \pm 0.12$ & $50.93 \pm 1.93$ & $26.15 \pm 3.37$ & $7.42 \pm 2.00$ \\
\hline
\end{tabular}

Cells starved at a serum free media showed a different pattern. The cells had a maximum of about $50 \%$ $\mathrm{G}_{1}$ accumulation the whole starvation period (Table 1). Within these days, percent of cells in $S$ phase decreased and likewise mean cell size also showed a decreasing pattern (Table 2). Although this decrease was not statistically significant. Figure 2 shows that cell count had a decreasing pattern in all starved cells. This is also obvious in microscopic images of the cells (Figure 3). As the figures 4 and 5 show, mitochondrial function and protein content of the cells also had a decreasing pattern in all starved cells. Levels of mitochondrial function and protein content of the cells all had a FBS\%-dependent pattern; the higher the FBS\%, the higher the level of mitochondrial function and protein content. 


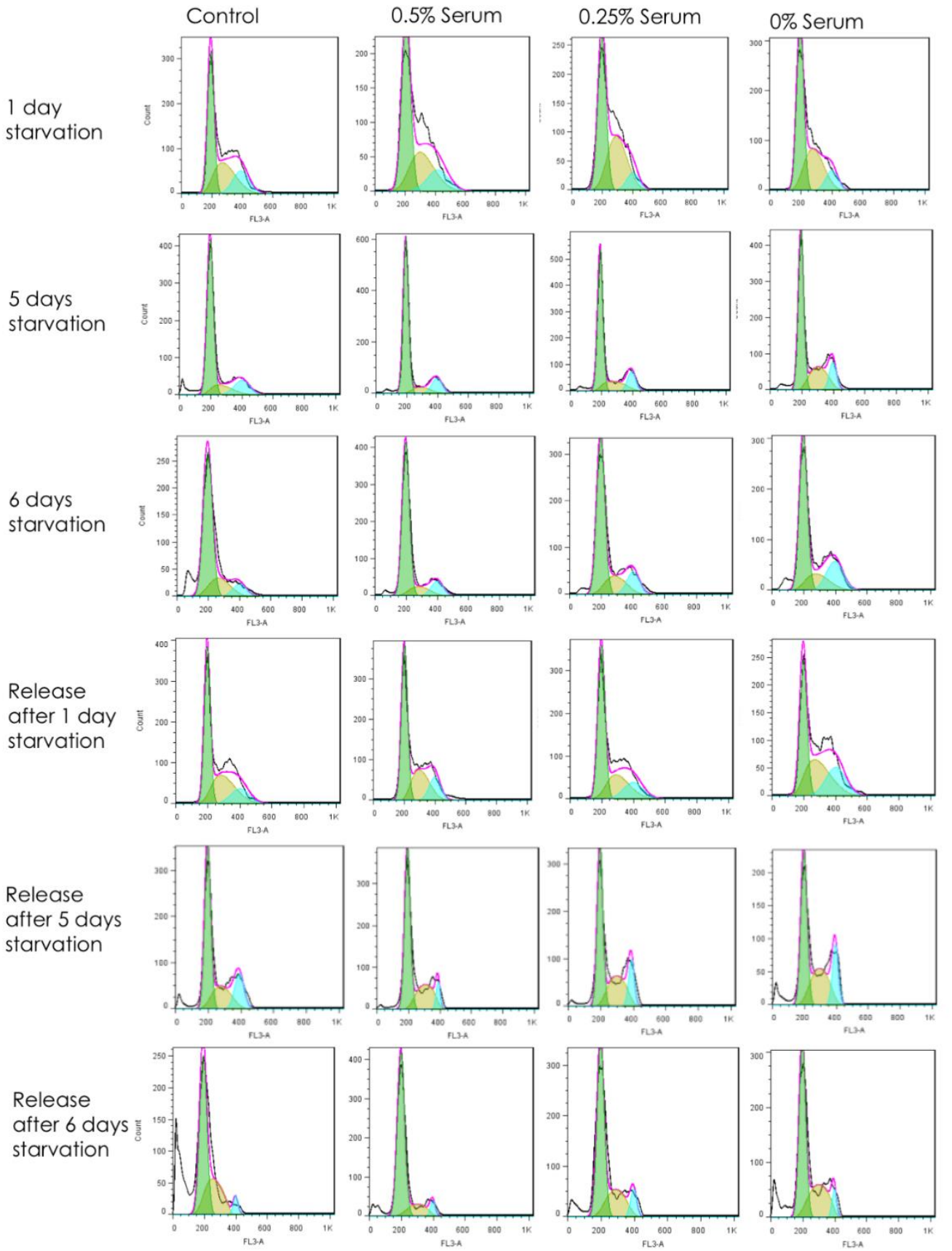

Figure 1. Histograms of A2780 cell distribution in the cell cycle phases. The cells were kept at 10, $0.5,0.25$ and $0 \%$ serum for 1 to 6 days. S and $\mathrm{R}$ represent starvation and release status, respectively. Selected histograms on days 1, 3 and 6 of the study are presented here. S stands for starvations and R stands for release status.

Releasing the cells, on the other hand, caused significant increase in mitochondrial function of the cells. Cells protein content also increased but to a less degree. That could be correlated with the decreased cell count of A2780 following release (Figure 2)

Cells starved at a serum free media showed a different pattern. The cells had a maximum of about $50 \%$ $\mathrm{G}_{1}$ accumulation the whole starvation period (Table 1). Within these days, percent of cells in $\mathrm{S}$ phase decreased and likewise mean cell size also showed a decreasing pattern (Table 2), although this decrease was not statistically significant.

Figure 2 shows that cell count had a decreasing pattern in all starved cells. This is also obvious in microscopic images of the cells (Figure 3). As the figures 4 and 5 show, mitochondrial function and protein content of the cells also had a decreasing pattern in all starved cells. 
Levels of mitochondrial function and protein content of the cells all had a FBS\%-dependent pattern; the higher the FBS\%, the higher the level of mitochondrial function and protein content. Releasing the cells, on the other hand, caused significant increase in mitochondrial function of the cells. Cells protein content also increased but to a less degree. That could be correlated with the decreased cell count of A2780 following release (Figure 2).

Table 2. Size distribution of A2780 cell line following 1 to 6 days of starvation in media containing $0.5 \%$, $0.25 \%$ and $0 \%$ serum, compared to control cells exposed to $10 \%$ serum. The table shows the mean cell size distribution of released cells for 24 hours following the determined starvation period. The test was performed in triplicate and data are presented as mean \pm SD.

\begin{tabular}{llllllll}
\hline \multirow{2}{*}{ Status } & \multirow{2}{*}{ Serum (\%) } & \multicolumn{6}{l}{ Time after starvation (day) } \\
\cline { 3 - 8 } & $\mathbf{1 0}$ & $385.5 \pm 2.1$ & $374 \pm 1.4$ & $361.5 \pm 2.1$ & $382 \pm 8.5$ & $329.5 \pm 0.7$ & $273.5 \pm 0.7$ \\
& $\mathbf{1 0}$ & $405.5 \pm 2.1$ & $402 \pm 16.8$ & $351.5 \pm 0.7$ & $383 \pm 4.2$ & $368.5 \pm 0.7$ & $325 \pm 2.8$ \\
Starvation & $\mathbf{0 . 5}$ & $412 \pm 2.8$ & $393 \pm 1.4$ & $355.5 \pm 0.7$ & $373.5 \pm 38.9$ & $368 \pm 19.8$ & $342 \pm 2.8$ \\
& $\mathbf{0 . 2 5}$ & $406 \pm 0.0$ & $402.5 \pm 5.6$ & $360.5 \pm 0.7$ & $330 \pm 9.8$ & $336.5 \pm 2.1$ & $334 \pm 2.8$ \\
& $\mathbf{0}$ & $409 \pm 19.8$ & $413 \pm 1.4$ & $370.5 \pm 9.2$ & $417.5 \pm 0.7$ & $381 \pm 2.8$ & $322.5 \pm 7.8$ \\
& $\mathbf{1 0}$ & $401 \pm 0.0$ & $420.5 \pm 6.4$ & $367.5 \pm 13.4$ & $410 \pm 5.6$ & $424.5 \pm 0.7$ & $406.5 \pm 3.5$ \\
Release in & $\mathbf{0 . 5}$ & $392 \pm 1.4$ & $414 \pm 1.4$ & $311.5 \pm 2.1$ & $399.5 \pm 16.3$ & $420 \pm 1.4$ & $428.5 \pm 2.1$ \\
& $\mathbf{0 . 2 5}$ & $430 \pm 9.9$ & $407.5 \pm 2.1$ & $346 \pm 2.8$ & $311.5 \pm 64.4$ & $376.5 \pm 0.7$ & $370.5 \pm 0.7$ \\
\hline
\end{tabular}

As stated before at the methods section, all cells were released in media containing $10 \%$ FBS following $24,48,72,96,120$ and 144 hours of starvation. The idea was to check if the cells are able to regenerate their strength after long-term metabolic stress. This boosted up cell proliferation in control cells (Figure 2) and their protein content (Figure 5) and mitochondrial function also increased (Figure 4). However, large number of cells produced too much metabolic waste and the media around the cells became yellowish, as an indicator of acidic environment. Then the percent of cells entering apoptotic phase increased, as evidenced by morphological studies (Figure 3) and flow cytometry data (Table 1). In other words, the results show that in control cells, media exchange can decrease the amount of cell accumulation in $\mathrm{G}_{1}$ phase and increase the percent of cells in S phase. For example, on day 5 of the study, $\mathrm{G}_{1} \%$ was $67.75 \pm 0.3$ and it reached to $51.65 \pm 0.66$ after a 24 -hour release. Meanwhile, cell\% in S phase reach to $22.5 \pm 0.26$, while it was $14.79 \pm 1.65$ before the release. At $0.5 \%$ starvation, also the same pattern was observed. Likewise, on day 5 of the study, $\mathrm{G}_{1} \%$ was $72.56 \pm 2.15$ and following release it reached to $55.06 \pm 5.29$. At the same time, cell $\%$ in $S$ phase was $10.67 \pm 2.23$ and after release it reached to $30.44 \pm 5.21$. The same pattern applies to the cells starved at $0.25 \%$ and $0 \% \mathrm{FBS}$.

Releasing the cells in optimum media also caused a slight, but not significant increase in cell size (Table 2) which can be explained by the increase in the percent of cells in $S$ phase. As observed in the microscopic images of Figure 3 and the cell count per $\mathrm{cm}^{2}$ in Figure 2 releasing the cells caused a significant decrease in cell count. Figures 4 and 5 show that mitochondrial function was significantly increased following releasing the cells in media containing 10\% FBS however, cells' protein content was not changed in control cells following a release, while in starved cells, protein content also increased, especially in the first days of the study. 

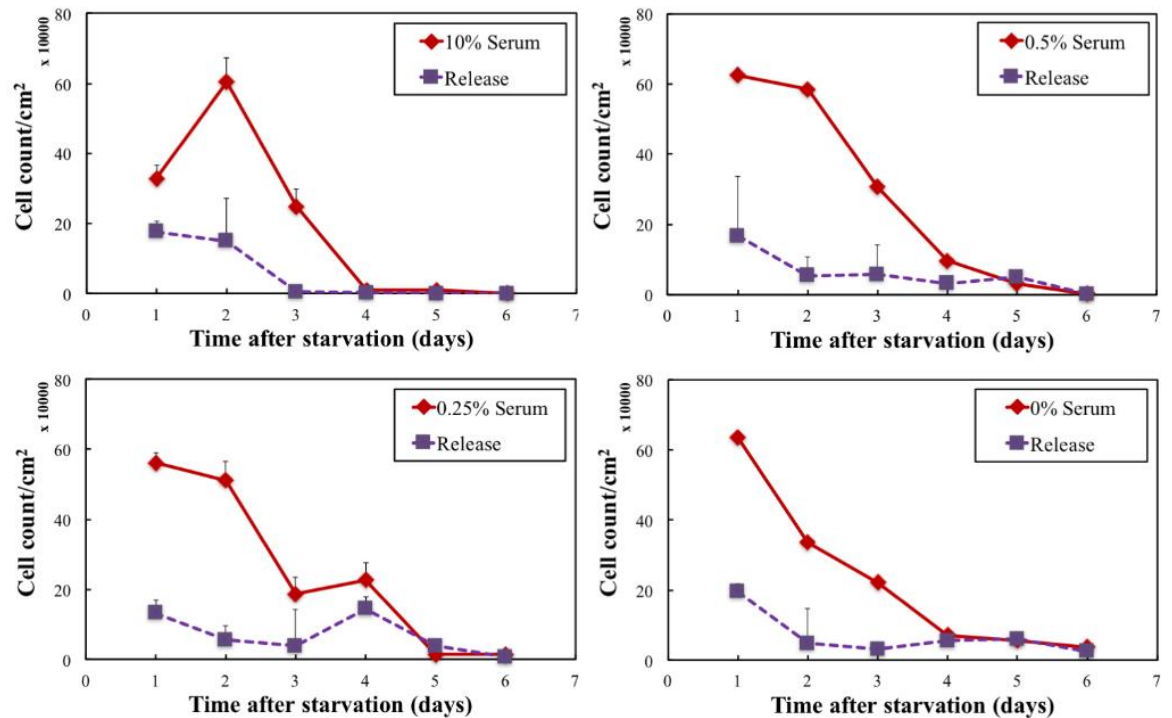

Figure 2. A2780 cell counts per $\mathrm{cm}^{2}$ in a 6-day study, following exposure to $10 \%, 0.5 \%, 0.25 \%$ and $0 \%$ serum concentration, or release for 24 hours in a media containing $10 \%$ serum. The test was performed in triplicate and data are presented as mean \pm SD.

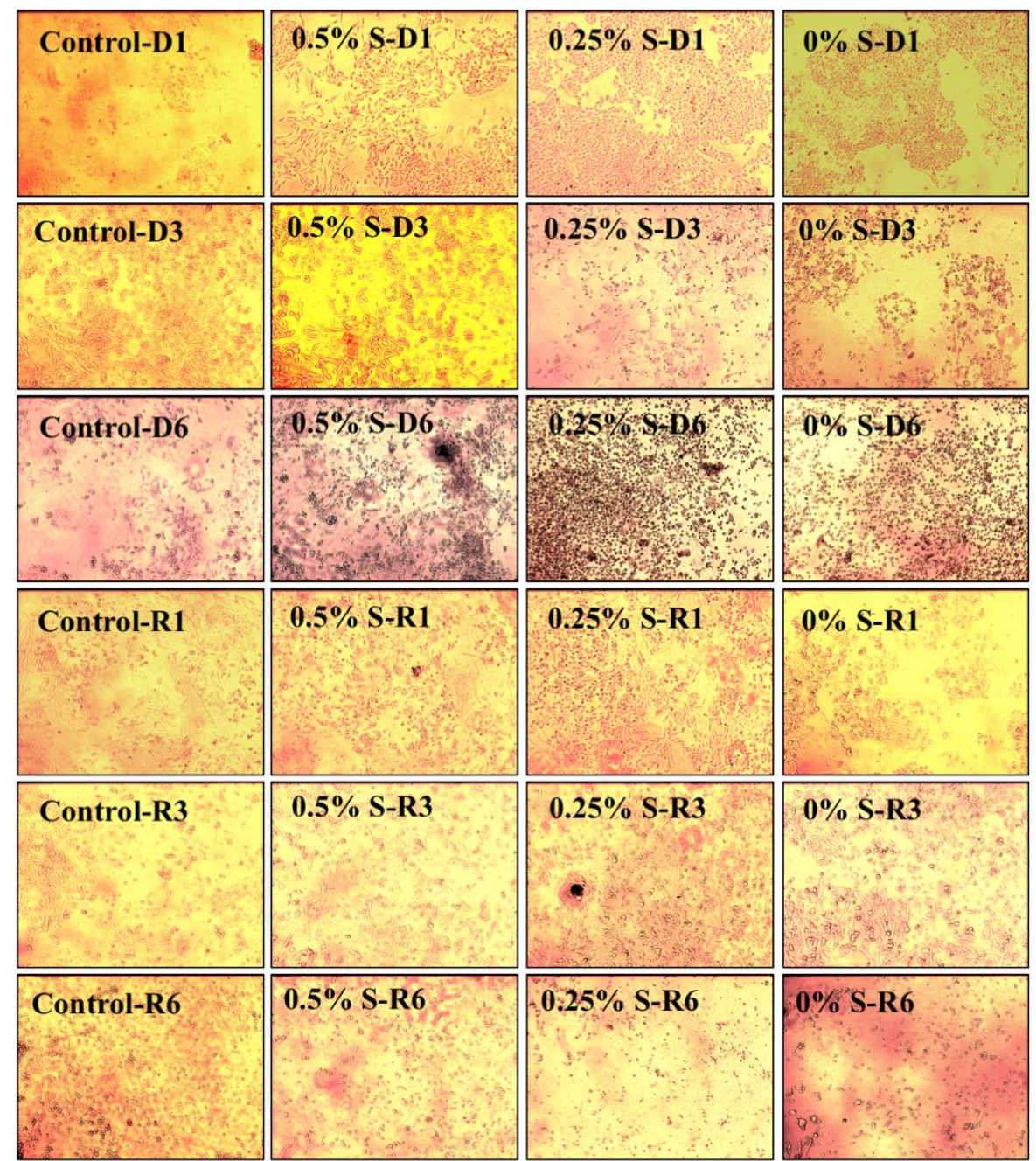

Figure 3. Morphology of A2780 cell line following exposure to 10\%, 0.5\%, $0.25 \%$ and $0 \%$ serum for 1 to 6 days (4X objective). D, S and R are abbreviations for day, serum and release, respectively. 


\section{DISCUSSION}

Tumour cells across a tumour are not metabolically at the same level. Cells on the outer layer of a tumour have sufficient access to vessels and hence sufficient oxygen exchange and waste removal happens and enough nutrition is provided for the cells. However, the cells in the deeper layers lack such conditions and moreover bear more physical stress. This is one of the reasons why the tumour cells do not respond evenly to the cytotoxic agents. In the current research, we have presented ovary cancer cells reaction towards different levels of metabolic stress. We considered 4 levels of FBS concentration; $10 \%$ as the control and $0.5,0.25 \%$ and $0 \%$ FBS as test groups. In order to mimic the physical stress, the cells reached the plateau phase, and then the experiment started. Furthermore, in order to study the cells' resistance capability against stress the cells were released in media containing 10\% FBS. All the experiments were studied for 6 days and evaluations were performed based on daily measurements.
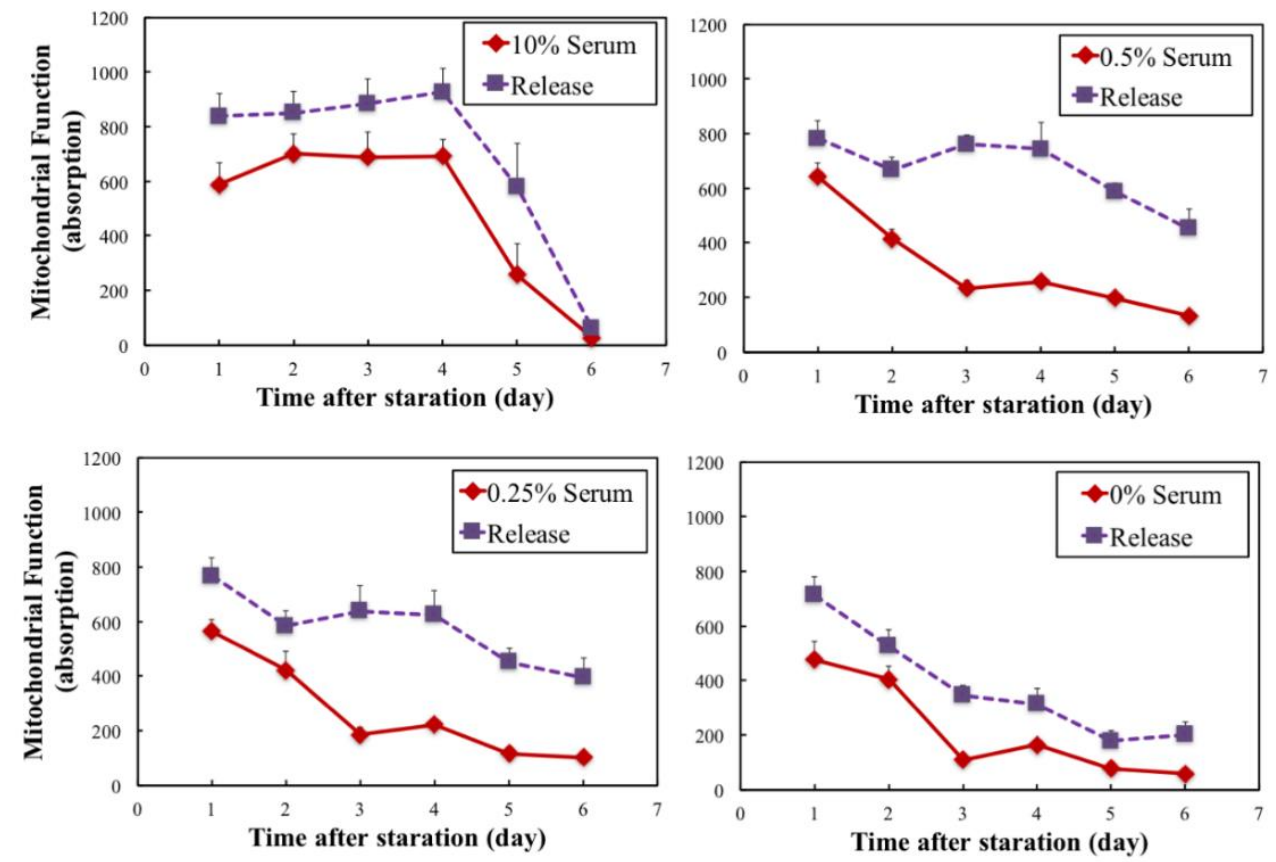

Figure 4. Mitochondrial function (absorption) in A2780 cell line based on MTT assay in a 6-day study, following exposure to $10 \%, 0.5 \%, 0.25 \%$ and $0 \%$ serum concentration, and a 24 -hour release in a media containing $10 \%$ serum. The test was performed in triplicate and data are presented as mean \pm SD.

The importance of this study was to evaluate ovary cancer cells reaction towards serum starvation. Normally, cells should have a natural flow through different phases of their life cycle including $G_{1}, S, G_{2}$ and $\mathrm{M}$ phase, when they finally divide and make 2 new cells. Various checkpoints control cells passing through these phases. One of the important checkpoints is believed to be in $\mathrm{G}_{1}$ phase, known as restriction point. This idea is first described by Arthur B. Pardee [23]. He explained that cells, when facing a serum restriction situation, will be accumulated in $\mathrm{G}_{1}$ phase until the environmental conditions are favourable enough for them to proceed. We have found similar responses in cancer cells, including A2780 ovary cancer cell line. Our results showed that the percent of cell accumulation in $\mathrm{G}_{1}$ phase is a factor of FBS concentration in the media. We noticed that at low FBS concentrations, cells tend to accumulate more in $\mathrm{G}_{1}$ phase in higher limits rather than lower limits. In other words, percent of cells accumulated in $\mathrm{G}_{1}$ was higher in the $0.5 \%$ FBS group, compared to the no-FBS group. However, our observation showed that at lower FBS concentration, the percent of cells accumulated in $\mathrm{G}_{1}$ was more stable and time-independent. For example, at a no-FBS concentration, the percent of cells accumulated in $\mathrm{G}_{1}$ phase did not change within the 6-day period of the study. Minute increase in FBS concentration resulted in an increasing pattern in the percent of cells accumulated in $\mathrm{G}_{1}$ phase. However, these explanations do not mean that these cells resist against dying. On contrary and as the results of cell count and microscopy show, metabolic stress causes less viable cell count during the 6 days of the study. This is also confirmed with the increased percent of sub-G $\mathrm{G}_{1}$ (apoptotic population) cells. This observation shows that these cells, at the lowest FBS access, somehow stop at $\mathrm{G}_{1}$ and some percent of $S$ phase cells enter either $\mathrm{G}_{2} / \mathrm{M}$ or sub$\mathrm{G}_{1}$ phase leading to death. When little amounts of FBS is accessible, the percent of cells in $\mathrm{G}_{1}$ substantially 
increases. On the other hand, providing the cells with $10 \%$ FBS for 24 hours, could release the cells from $\mathrm{G}_{1}$ phase. This 24 hours let the cells slowly enter S phase, a time length which was not long enough for these cells to proliferate and increase the cell count, as confirmed by microscopic images and trypan blue assay results. It can be concluded that in stress situations, cancer cells try their best to resist against death. This was also shown for melanoma and lung cancer. A2780 seems to be weaker in resisting against death compared to those two cancers. Some evidences claim that cancer cells with defects in the apoptosis pathways, use the other catabolic pathway of autophagy to substitute energy resources and provide energy for cells' metabolism [24, 25].

The other discussion on the observations in the current study could be based on the "Warburg Effect". In normal cells, the available nutrients around the cells would be taken up unless some growth factors stimulate the cells to do so. Cancer cells, due to some mutations, are able to uptake any nutrients independently from growth factors $[12,26]$, and this is what Otto Warburg showed for glucose consumption in cancer cells [27, 28]. Also, it is now known that in cultured cells, glutamine is also the other micro-nutrient which is highly used in cancer cells. Glucose and glutamine were both accessible to our cultured cells in our study. These two micronutrients provide sufficient carbon, nitrogen and energy for the cells. Some portions of glucose are consumed in mitochondria to provide ATP through oxidative phosphorylation and some portions of glucose are used to provide substrates for Acetyl-CoA production. Acetyl-CoA will later be used to produce fatty acids, glycolysis intermediates for unnecessary amino acids and ribose for nucleotide production [12]. Glutamine, further to providing nitrogen for the production of unnecessary amino acids, can also produce NADPH through glutaminolysis. Hence the terminology of glutamine addiction has arisen [29, 30]. Similarly, glutamine can provide nucleotides for DNA production and is also connected to the mTOR pathway to control the cell cycle, growth and nutrition state of the cells [29, 31, 32]. As it is already known, mTOR pathway has gained a lot of attention in cancer. It is because this pathway is involved in controlling processes that require or make huge amounts of nutrients and energy and hence this pathway is involved in cell proliferation and cell growth [42].

These mechanisms, however, cannot explain the descending trend of cell count, protein content and mitochondrial function within the last days of the study. In general, the cells were so weak that control cells or the test cells' count did not differ significantly. Metabolic stress caused a significantly lower mitochondrial function in test cells compared to control cells, yet a FBS concentration-dependent manner was observed. Cells' protein content also showed a FBS concentration-dependent manner. So, generally it could be concluded that metabolic stress caused a significant derive for A2780 cells to die, while still some degrees of resistance was observable. The clue for cell resistance was the percent of remaining live cells accumulated in $\mathrm{G}_{1}$ phase and how they released from $G_{1}$ phase when exposed to $10 \%$ FBS. Following releasing the cells, both the mitochondrial function and the protein content of the cells increased, though cell count did not increase. This shows that these cells, though less resistant against harsh conditions compared to skin and lung cancer cells, still resist dying to some degrees.

Though it is believed that autophagy can provide suitable conditions for cancer cells to live longer, and play roles in cancer resistance [11, 28, 33-35], it is shown that in cisplatin-resistant A2780 cell line, autophagy has a protective role against cell death and blocking autophagy can make the cells more susceptible to death [36]. Based on the current observations and results in this study, it is possible that autophagy pathway has some defects in this cell line, though this needs further tests to be proved.

\section{CONCLUSION}

Cancer cells have different behaviors from normal cells. They can adopt to the conditions around them, resist against death and apoptotic pathways. Each cancer cell has an exclusive threshold against harsh conditions. The significance of this study was to monitor A2780 cells reaction to different levels of metabolic stress in a long-term period of time. We concluded that this cell lines have less resistance against metabolic stress, compared to skin and lung cancer cells. This lower level of resistance does not necessarily mean that the cells completely gave up to metabolic stress. In fact, the remaining live cells were highly accumulated in $\mathrm{G}_{1}$ phase and upon re-exposure to favorable conditions, where $10 \% \mathrm{FBS}$ is provided and all the waste is discarded, the cells released from $\mathrm{G}_{1}$ and started reconstructing inner engines, as evidenced by mitochondrial function and protein content. 


\section{MATERIALS AND METHODS}

\subsection{Materials}

Human ovary carcinoma A2780 (C461) cell line was purchased from National Cell Bank of Iran. Fetal bovine serum (FBS), DMEM media, penicillin/streptomycin and trypsin were purchased from GIBCO ${ }^{\circledR}$. All other used materials were from SIGMA ${ }^{\circledR}$.
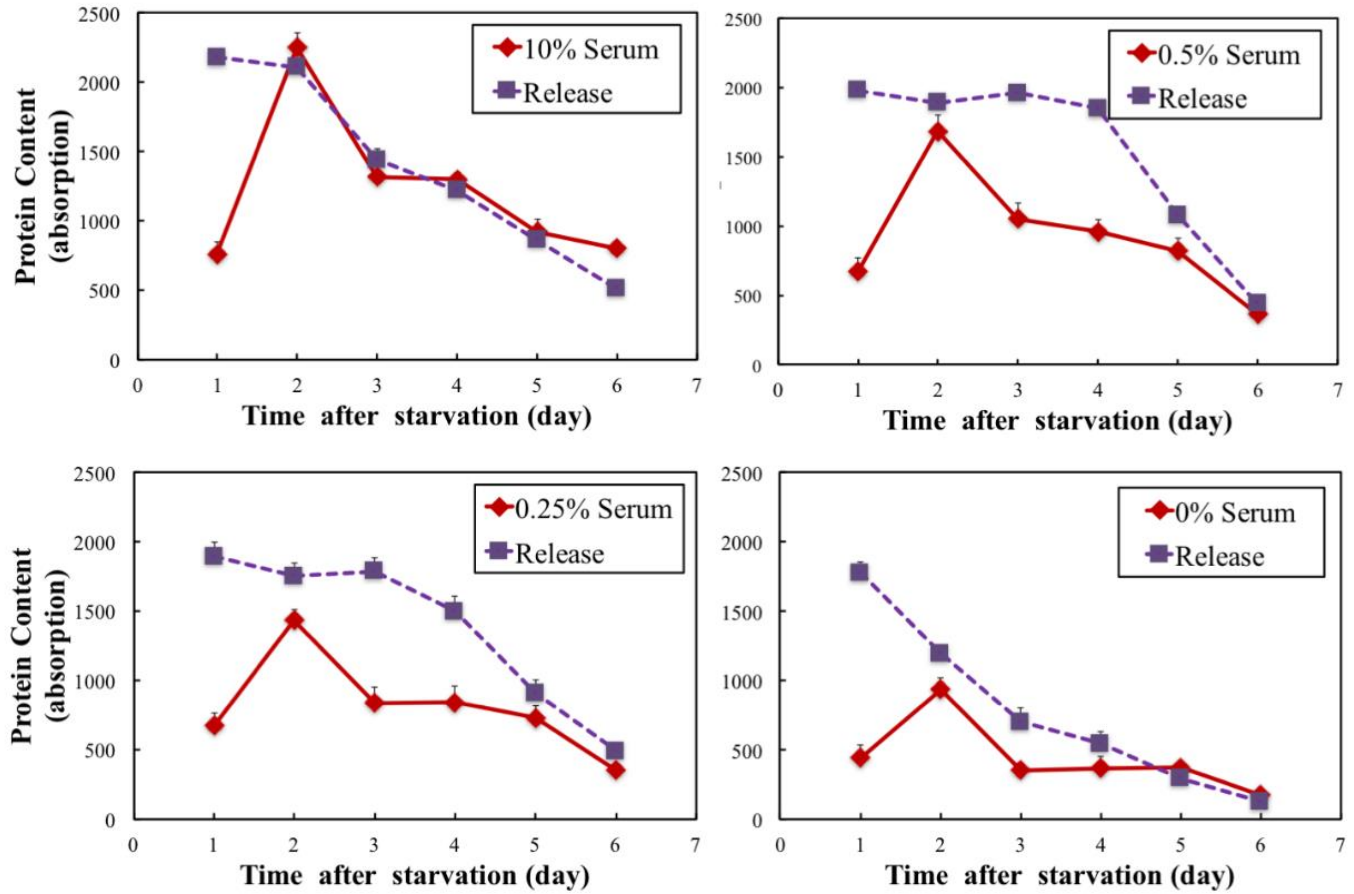

Figure 5. Protein content (absorption) in A2780 cell line based on SRB assay in a 6-day study, following exposure to $10 \%, 0.5 \%, 0.25 \%$ and $0 \%$ serum concentration, and a 24 -hour release in a media containing $10 \%$ serum. The test was performed in triplicate and data are presented as mean \pm SD.

\subsection{Cell culture methods}

A2780 cells were thawed and passaged three times before the experiment. Seeding density of 4000 cells $/ \mathrm{cm}^{2}$ was chosen and when the cells reached the plateau phase, the experiment started [21, 37]. To have an in vitro model of A2780 cells to mimic different levels of metabolic activity of cells in a tumor, low FBS concentrations were considered. Figure 6 depicts the schematic flow chart of the study design. Briefly, media supplemented with $10 \%$ FBS was considered as control and test groups were exposed to media containing 0.5 , 0.25 and $0 \%$ FBS. The cells bore metabolic stress for $24,48,72,96,120$ and 144 hours. At 24 hour intervals, the cells were tested for cell cycle, size, morphology, proliferation, mitochondrial function and protein content, as described below. Furthermore, to test the ability of the cells to regain strength and get back to higher levels of metabolic activity, the cells were released in media containing 10\% FBS. The release time took place after 24, $48,72,96,120$ and 144 hours of starvation and lasted for 24 hours. Then the cells were tested as described below.

\subsection{Flow cytometry, cell cycle and size measurement}

Cells' cycle and size was studied using a flow cytometer (BD FACSCalibur ${ }^{\mathrm{TM}}$ ). 1×106 cells were trypsinized, washed using ice-cold phosphate buffer saline and stained with a propidium iodide solution containing RNase and triton X-100 [21]. Cells distribution in the cycle was analyzed using FlowJo ${ }^{\circledR}$ software, version 7.6.1. This software was also used to analyze changes in mean cell size, based on the method described by Rathmell et al. to use geometrical mean of forward scattering laser of distribution of cells [38]. 


\subsection{Cell proliferation assay}

Trypan blue assay was used to study cells' proliferation. At defined times, the cells were trypsinized and mixed with equal volume of trypan blue dye. Live cells were counted on a hemocytometer under an inverted light microscope [39].

\subsection{Morphological studies}

Morphological changes of the cells were studied using an inverted light microscope and Moticam Pro (CCD) camera [40].

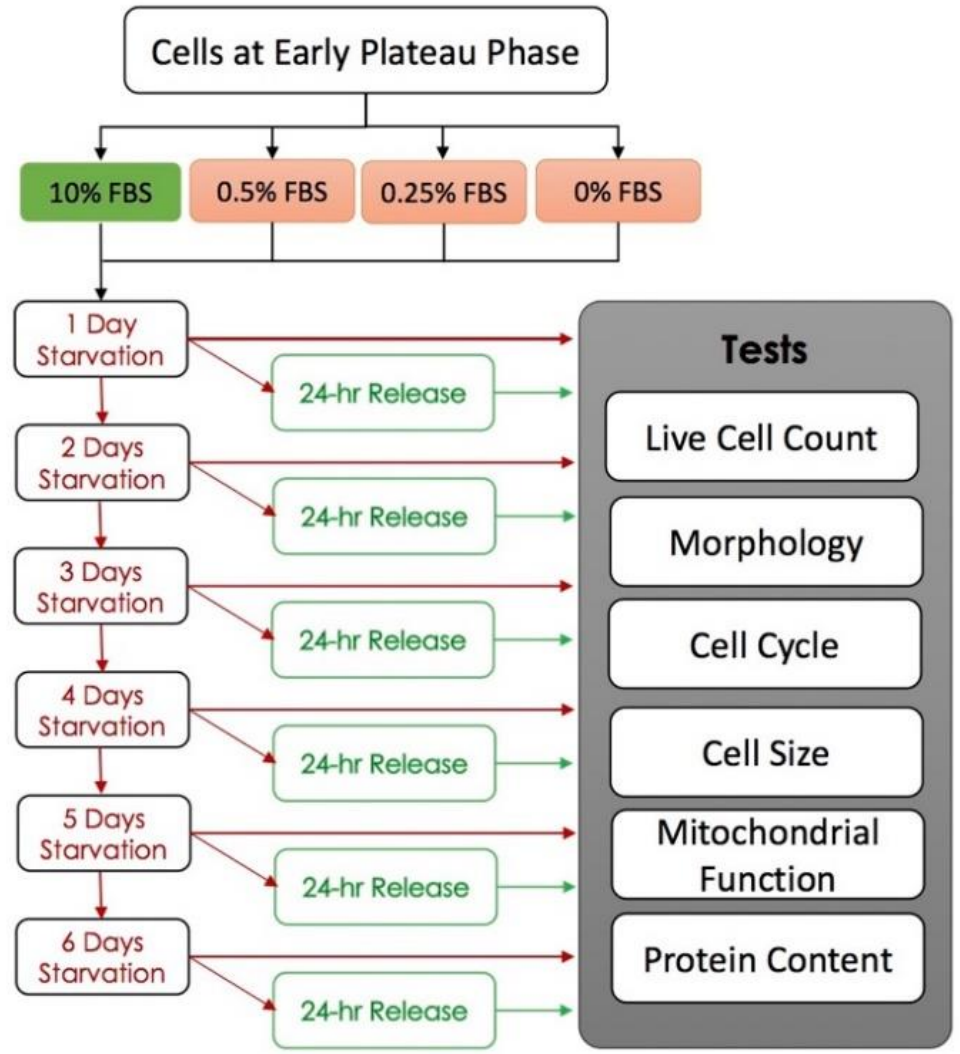

Figure 6. Schematic flowchart of the study design.

\subsection{Mitochondrial function of the cells}

MTT assay was used to study the mitochondrial function of the cells, based on the method previously described [41]. Briefly, the cells were seeded in 96-well plates and at the time of the experiment, they were exposed to MTT solution $(10 \% \mathrm{v} / \mathrm{v})$ for 4 hours. Then the supernatant was replaced with DMSO and the absorption was recorded at $570 \mathrm{~nm}$.

\subsection{Protein content of the cells}

SRB assay was used to study the protein content of the cells, as previously described [1]. At the time of the experiment, cells in 96-well plates were fixed using ice-cold tricholoroacetic acid. The cells were washed and Sulforhodamine B dye $(0.4 \% \mathrm{v} / \mathrm{w})$ was added to wells for 30 minutes. Finally, the wells were washed and tris buffer was added to wells and the absorption was read at $540 \mathrm{~nm}$.

\subsection{Statistical analysis}

Statistical analysis was done using GraphPad PRISM ${ }^{\circledR}$ version 5. All comparisons were done with twoway analysis of variance with $p$ value of 0.05 . All tests were done in triplicate and mean \pm standard deviation is used to present the results were applicable. 
Acknowledgements: The authors would like to express their appreciation to SBMU Pharmaceutical Sciences Research Center for the financial support.

Author contributions: Concept - F.H.S; Design - M.N.; Supervision - F.H.S; Resource - F.H.S in SBMU Pharmaceutical Sciences Research Center; Materials - F.H.S in SBMU Pharmaceutical Sciences Research Center; Data Collection and/or Processing - M.N.; Analysis and/or Interpretation - M.N.; Literature Search - M.N.; Writing - M.N.; Critical Reviews - M.N., F.H.S

Conflict of interest statement: The authors declare no conflict of interest.

\section{REFERENCES}

[1] Nakhjavani M, Zarghi A, Shirazi FH. Cytotoxicity of selected novel chalcone derivatives on human breast, lung and hepatic carcinoma cell lines. Iran J Pharm Res. 2014; 13(3): 953-958.

[2] Vakili N, Nakhjavani M, Mirzayi H, Shirazi F. Studying silibinin effect on human endothelial and hepatocarcinoma cell lines. Res Pharm Sci. 2012; 7(5): S174.

[3] Shirazi FH, Zarghi A, Kobarfard F, Zendehdel R, Nakhjavani M, Arfaiee S, Zebardast T, Mohebi S, Anjidani N, Ashtarinezhad A. Remarks in successful cellular investigations for fighting breast cancer using novel synthetic compounds. In: Gunduz M (Ed). Breast Cancer-Focusing Tumor Microenvironment, Stem cells and Metastasis, Croatia, InTech Europe, 2011, pp. 85-102.

[4] Sarafraz M, Hormozi F. Comparatively experimental study on the boiling thermal performance of metal oxide and multi-walled carbon nanotube nanofluids. Powder Technol. 2016; 287: 412-430.

[5] Sarafraz M, Hormozi F. Experimental investigation on the pool boiling heat transfer to aqueous multi-walled carbon nanotube nanofluids on the micro-finned surfaces. Int J Therm Sci. 2016; 100: 255-266.

[6] Sarafraz MM. Nucleate pool boiling of aqueous solution of citric acid on a smoothed horizontal cylinder. Heat Mass Transfer. 2012; 48(4): 611-619.

[7] Kamalgharibi M, Hormozi F, Zamzamian SAH, Sarafraz M. Experimental studies on the stability of CuO nanoparticles dispersed in different base fluids: influence of stirring, sonication and surface active agents. Heat Mass Transfer. 2016; 52(1): 55-62.

[8] Sarafraz M, Peyghambarzadeh S, Alavifazel S. Enhancement of nucleate pool boiling heat transfer to dilute binary mixtures using endothermic chemical reactions around the smoothed horizontal cylinder. Heat Mass Transfer. 2012; 48(10): 1755-1765

[9] Sarafraz M. Experimental investigation on pool boiling heat transfer to formic acid, propanol and 2-butanol pure liquids under the atmospheric pressure. J Appl Fluid Mech. 2013; 6(1): 73-79.

[10] Sarafraz M, Arya A, Hormozi F, Nikkhah V. On the convective thermal performance of a CPU cooler working with liquid gallium and $\mathrm{CuO}$ /water nanofluid: A comparative study. Appl Therm Eng. 2017; 112: 1373-1381.

[11] Hoare M, Young AR, Narita M, editors. Autophagy in cancer: having your cake and eating it. Semin Cancer Biol; 2011; 21(6): 397-404.

[12] DeBerardinis RJ, Lum JJ, Hatzivassiliou G, Thompson CB. The biology of cancer: metabolic reprogramming fuels cell growth and proliferation. Cell Metab. 2008; 7(1): 11-20.

[13] Hanahan D, Weinberg RA. The hallmarks of cancer. Cell. 2000; 100(1): 57-70.

[14] Chisholm RH, Lorenzi T, Clairambault J. Cell population heterogeneity and evolution towards drug resistance in cancer: biological and mathematical assessment, theoretical treatment optimisation. BBA-Gen Subjects. 2016; 1860(11): 2627-2645.

[15] Danhier P, Bański P, Payen VL, Grasso D, Ippolito L, Sonveaux P, Porporato PE. Cancer metabolism in space and time: Beyond the Warburg effect. BBA-Bioenergetics. 2017; 1858(8): 556-572.

[16] Hsieh JJ, Manley BJ, Khan N, Gao J, Carlo MI, Cheng EH, editors. Overcome tumor heterogeneity-imposed therapeutic barriers through convergent genomic biomarker discovery: a braided cancer river model of kidney cancer. Semin Cell Dev Bio; 2017; 64: 98-106.

[17] Ebrahim K, Vatanpour H, Zare A, Shirazi FH, Nakhjavani M. Anticancer activity a of Caspian cobra (Naja Naja oxiana) snake venom in human cancer cell lines via induction of apoptosis. Iran J Pharm Res. 2016; 15(Suppl): 101112 
[18] Siegel R, Naishadham D, Jemal A. Cancer statistics, 2013. CA-Cancer J Clin. 2013; 63(1): 11-30.

[19] Chan J, Cheung M, Husain A, Teng N, West D, Whittemore A, Berek J, Osann K. Patterns and progress in ovarian cancer over 14 years. Obstet Gynecol. 2006; 108(3 Pt 1): 521-528.

[20] Nikounezhad N, Nakhjavani M, Shirazi FH. Cellular glutathione level does not predict ovarian cancer cells' resistance after initial or repeated exposure to cisplatin. J Exp Ther Oncol. 2017; 12(1): 1-7.

[21] Nakhjavani M, Nikounezhad N, Ashtarinezhad A, Shirazi FH. Human Lung Carcinoma Reaction against Metabolic Serum Deficiency Stress (Autumn 2016). Iran J Pharm Res. 2016; 15(4): 817-823.

[22] Nakhjavani M, Stewart DJ, Shirazi FH. Effect of steroid and serum starvation on a human breast cancer adenocarcinoma cell line. J Exp Ther Oncol. 2017; 12(1): 25-34.

[23] Pardee AB. G1 events and regulation of cell proliferation. Science. 1989; 246(4930): 603-608.

[24] Degenhardt K, Mathew R, Beaudoin B, Bray K, Anderson D, Chen G, Mukherjee C, Shi Y, Gélinas C, Fan Y. Autophagy promotes tumor cell survival and restricts necrosis, inflammation, and tumorigenesis. Cancer Cell. 2006; 10(1): 51-64.

[25] Lum JJ, Bauer DE, Kong M, Harris MH, Li C, Lindsten T, Thompson CB. Growth factor regulation of autophagy and cell survival in the absence of apoptosis. Cell. 2005; 120(2): 237-248.

[26] Hsu PP, Sabatini DM. Cancer cell metabolism: Warburg and beyond. Cell. 2008; 134(5): 703-707.

[27] Warburg O. On the origin of cancer. Science. 1956; 123(3191): 309-314.

[28] Warburg O, Wind F, Negelein E. The metabolism of tumors in the body. J Gen Physiol. 1927; 8(6): 519-530.

[29] Bhutia YD, Babu E, Prasad PD, Ganapathy V. The amino acid transporter SLC6A14 in cancer and its potential use in chemotherapy. Asian J Pharm Sci. 2014; 9(6): 293-303.

[30] Vander Heiden MG, Cantley LC, Thompson CB. Understanding the Warburg effect: the metabolic requirements of cell proliferation. Science. 2009; 324(5930): 1029-1033.

[31] Dibble CC, Manning BD. Signal integration by mTORC1 coordinates nutrient input with biosynthetic output. Nat Cell Biol. 2013; 15(6): 555-564.

[32] Jewell JL, Guan K-L. Nutrient signaling to mTOR and cell growth. Trends Biochem Sci. 2013; 38(5): $233-242$.

[33] Amaravadi RK, Yu D, Lum JJ, Bui T, Christophorou MA, Evan GI, Thomas-Tikhonenko A, Thompson CB. Autophagy inhibition enhances therapy-induced apoptosis in a Myc-induced model of lymphoma. J Clin Invest. 2007; 117(2): 326-336.

[34] Liu D, Yang Y, Liu Q, Wang J. Inhibition of autophagy by 3-MA potentiates cisplatin-induced apoptosis in esophageal squamous cell carcinoma cells. Med Oncol. 2011; 28(1): 105-111.

[35] Qadir M, Kwok B, Dragowska W, To K, Le D, Bally M, Gorski SM. Macroautophagy inhibition sensitizes tamoxifenresistant breast cancer cells and enhances mitochondrial depolarization. Breast Cancer Res Tr. 2008; 112(3): 389-403.

[36] Bao L, Jaramillo MC, Zhang Z, Zheng Y, Yao M, Zhang DD, Yi X. Induction of autophagy contributes to cisplatin resistance in human ovarian cancer cells. Mol Med Rep. 2015; 11(1): 91-98.

[37] Nikounezhad N, Nakhjavani M, Shirazi FH. Generation of cisplatin-resistant ovarian cancer cell lines. Iran J Pharm Sci. 2016; 12(1): 11-20.

[38] Rathmell JC, Vander Heiden MG, Harris MH, Frauwirth KA, Thompson CB. In the absence of extrinsic signals, nutrient utilization by lymphocytes is insufficient to maintain either cell size or viability. Mol Cell. 2000; 6(3): 683692.

[39] Nakhjavani M, Ashtarinezhad A, Shirazi F. Studying the effect of methylparaben and propylparaben on growth curve of human breast adenocarcinoma cell line. Res Pharm Sci. 2012; 7(5): S175.

[40] Nakhjavani M, Nikounezhad N, H Shirazi F. Effects of Cells Density and Positioning on Optimized FTIR Biospectroscopy. Iran J Pharm Sci. 2014; 10(2): 61-68.

[41] Jamali B, Nakhjavani M, Hosseinzadeh L, Amidi S, Nikounezhad N, Shirazi FH. Intracellular GSH alterations and its relationship to level of resistance following exposure to cisplatin in cancer cells. Iran J Pharm Res. 2015; 14(2): 513519 .

[42] Mathieu L, Sabatini DM. mTOR signaling in growth control and disease. Cell. 2012; 149(2): 274-293. 